\title{
Globalização, desemprego e (nova) pobreza: Estudo sobre impactes nas sociedades portuguesa $\mathrm{e}$ brasileira
}

Globalization, Unemployment and the (New) Poverty: Their impacts upon

Portuguese and Brazilian societies

Mondialisation, chômage et (nouvelle) pauvreté : étude sur des impacts dans les sociétés portugaise et brésilienne

\section{Adilson Gennari e Cristina Albuquerque}

\section{OpenEdition}

\section{Journals}

\section{Edição electrónica}

URL: http://journals.openedition.org/rccs/3970

DOI: $10.4000 /$ rccs.3970

ISSN: 2182-7435

\section{Editora}

Centro de Estudos Sociais da Universidade de Coimbra

\section{Edição impressa}

Data de publição: 1 março 2011

Paginação: $51-73$

ISSN: 0254-1106

\section{Refêrencia eletrónica}

Adilson Gennari e Cristina Albuquerque, « Globalização, desemprego e (nova) pobreza: Estudo sobre impactes nas sociedades portuguesa e brasileira », Revista Crítica de Ciências Sociais [Online], 92 | 2011, posto online no dia 01 novembro 2012, consultado o 10 dezembro 2020. URL : http:// journals.openedition.org/rccs/3970 ; DOI : https://doi.org/10.4000/rccs.3970 


\section{ADILSON GENNARI CRISTINA ALBUQUERQUE}

\section{Globalização, desemprego e (nova) pobreza: Estudo sobre impactes nas sociedades portuguesa e brasileira}

O presente artigo constitui-se como um contributo para uma reflexão sobre possíveis conexões entre os processos de globalização económica, as mudanças no mercado de trabalho e os novos perfis da pobreza. O debate, enquadrado em dois contextos económicos distintos, o português (com ritmos de crescimento lentos e deficitários, com uma grave crise social e dificuldades de afirmação económica e política no contexto europeu e mundial) e o brasileiro (com uma economia emergente e dinâmica, com fortes taxas de crescimento e uma tendência de redução nos índices de miséria e de pobreza), permite-nos posicionar alguns dos impactes, económicos e sociais, decorrentes das pressões globais para a competitividade económica e potenciadores da emergência de novas formas de pobreza e de precarização social e laboral nas duas sociedades.

Palavras-chave: globalização, desemprego, pobreza, interdependência económica, Portugal, Brasil.

\section{Introdução}

A globalização constitui-se hoje como uma chave analítica incontornável para a compreensão do conjunto de exigências, constrangimentos, potencialidades e transformações ${ }^{1}$ ocorridas, em diversos contextos, sobretudo nas últimas décadas.

Muitos analistas tendem a conceber a globalização como um fenómeno essencialmente económico, traduzido no incremento das trocas comerciais internacionais e do fluxo de capitais, secundarizando, desse modo, as dimensões de interdependência a nível político, social, cultural e tecnológico que

\footnotetext{
${ }^{1}$ Mudanças essas que evidenciam novas configurações do regime capitalista avançado, e do estatuto do trabalho nas sociedades contemporâneas, a que Offe (1989) chama "capitalismo desorganizado" e Sennet (2001) "capitalismo flexível".
} 
determinam as tramas de complexidade das sociedades contemporâneas. Com efeito, para além da compreensão de factores associados à crescente interdependência das economias, é importante que sejam considerados, em paralelo e de modo substancial, os impactes sociopolíticos dela decorrentes, nomeadamente, os processos de complexificação das desigualdades à escala mundial, bem como os mecanismos de decisão global, potenciadores da emergência, ou da fragmentação, das autonomias locais e de novas formas de participação cívica e política dos cidadãos.

Neste contexto, parece-nos essencial promover um debate em torno das actuais reconfigurações do trabalho, constituído desde há muitas décadas como o principal mecanismo de integração e de participação socioeconómica, face a dinâmicas cada vez mais complexas e imprevisíveis, ao mesmo tempo causas e consequências da globalização. A mutação do perfil dos trabalhadores e do trabalho, a precariedade e a aleatoriedade como factores estruturantes das vivências actuais, a fragmentação dos pilares dos modelos sociais e a cada vez mais difícil conciliação entre social e económico, entre equidade e competitividade, colocam em primeira linha o debate sobre as conexões entre pobreza e emprego na actualidade.

Sob tais pressupostos, procuraremos, no presente artigo, reflectir essencialmente sobre as reconfigurações do perfil do trabalhador e do trabalho, como categoria social, económica e politicamente construída, bem como ponderar possíveis associações entre a crise actual do emprego, num mundo globalizado, e o incremento de novas formas de pobreza. Para esse efeito ilustraremos a nossa análise com dados de um país considerado "emergente" (com elevados ritmos de crescimento económico), o Brasil, e de um país integrado na União Europeia, Portugal (com um crescimento económico deficitário), que procura gerir, de forma instável, os (des)equilíbrios entre equidade social e eficiência económica. Dito de outro modo, pretendemos discutir, por um lado, as transformações que tendem a reconfigurar o mercado de trabalho nos dois contextos e os impactes diferenciados dos processos de globalização em curso e, por outro, percepcionar as possíveis conexões com a pobreza, estrutural e/ou emergente, em tais contextos e condições.

\section{Impactes económicos da globalização nas sociedades portuguesa e brasileira}

A globalização do capitalismo, como salienta Anderson (1995), implicou a adopção de um conjunto de medidas e de recomendações de política económica e de política externa, semelhantes em quase todos os países do mundo (Consenso de Washington ou neoliberal), porém, com impactes 
distintos consoante a respectiva capacidade de adaptação económica aos novos desafios e o tecido social e político pré-existente. Dentro desse conjunto de medidas, as mais relevantes incidiram sobre os seguintes aspectos: a) disciplina fiscal; b) priorização dos gastos públicos no sentido de combate ao défice; c) reforma tributária; d) liberalização financeira; e) flexibilização do regime cambial; f) abertura comercial; g) estímulo ao investimento directo estrangeiro; h) privatização; i) desregulamentação das relações de trabalho e j) regulação da propriedade intelectual.

Um dos pilares que potenciou o processo de globalização económica em curso foi de facto a desregulamentação crescente em benefício da liberalização dos fluxos internacionais de capitais. Deste modo, nas últimas décadas, a matriz liberal ocidental tende a afirmar-se como quadro referencial não somente das relações económicas, mas também das relações sociais e culturais (Giddens, 1990; Lipietz, 1992), colocando em evidência um conjunto de mudanças profundas e articuladas (ora de sinal positivo, ora negativo, consoante o prisma de análise), muitas das quais são simultaneamente causa e consequência dos processos em curso.

Com efeito, se a globalização pode ser concebida como uma oportunidade de desenvolvimento e de afirmação no contexto internacional para certos países, para outros, mais frágeis social e economicamente, pode constituir-se como um mecanismo de desagregação multidimensional ou, na melhor das hipóteses, como um desafio importante a suplantar.

O caso português é particularmente elucidativo no que concerne às dificuldades de resposta adequada e atempada a um tal desafio. É um facto que a entrada de Portugal na União Europeia, em 1986, se traduziu em mutações nas formas tradicionais de regulação social, económica, política e cultural (Santos, 2001; Hespanha e Carapinheiro, 2001). Porém, a competitividade e a internacionalização política e económica dela decorrentes têm-se constituído como desafios de relevo perante um tecido económico maioritariamente frágil e, em larga medida, resistente a uma cultura de inovação e investigação. ${ }^{2}$

A estagnação da economia e a incapacidade de acompanhar, de forma perene e consistente, os ritmos de crescimento e desenvolvimento da União Europeia; o aumento exponencial do desemprego nas últimas décadas; os baixos salários; um tecido empresarial pouco competitivo; um défice das contas públicas que atinge em 2010, de acordo com os dados do Instituto

\footnotetext{
${ }^{2}$ Diversos analistas económicos apontam, como característica marcante da economia portuguesa, a coexistência, por vezes no mesmo território local, de indústria e serviços de ponta (nomeadamente no sector tecnológico) a par de micro, pequenas e médias empresas com um nível de desenvolvimento e de competitividade manifestamente insuficientes.
} 
Nacional de Estatística (INE, Abril de 2011), os 9,1\%, ${ }^{3}$ a par do fortíssimo endividamento externo das empresas e do país (com os juros da dívida soberana a 10 anos a atingirem, em Junho de 2011, o valor histórico de 10,3\%), colocam Portugal como um dos países em situação de maior vulnerabilidade face ao exterior e, como tal, um dos menos preparados para responder aos desafios actuais da globalização.

Com efeito, o nível das exportações, profundamente deficitário por referência ao das importações, a predominância do sector dos serviços e de empresas com menos de 10 pessoas (que correspondiam, em 2008, em percentagem do total de empresas, a 95,5\%, de acordo com dados da PorData, Abril 2011) e a dependência de combustíveis minerais ${ }^{4}$ contribuem fortemente para o défice da balança comercial. Em acréscimo, o nível de inovação e de aposta na Investigação e Desenvolvimento está muito aquém dos restantes parceiros europeus, sendo manifestamente insuficiente (apenas 1,7 \% do PIB em 2009) num país que necessita de encontrar a sua diferencialidade e excelência em contextos globais e altamente competitivos.

Do mesmo modo, em termos estruturais, a necessidade inequívoca de reformas profundas em sectores basilares da sociedade portuguesa, como sejam a educação, a administração pública, a justiça, a fiscalidade, tem sido condicionada por ciclos eleitorais e interesses instalados, encerrando o país num dos seus paradoxos constitutivos: a afirmação da sua modernidade, mantendo sistemas e processos arcaicos e clientelistas (Ferrera et al., 2011).

A visível e persistente fragilidade económica de Portugal é assim potenciada pela globalização, abrindo espaço a lógicas especulativas (veja-se a pressão exercida pelas agências internacionais de notação financeira, que em muito condicionou o pedido de resgate financeiro ao Fundo Monetário Internacional e à União Europeia) e evidenciando as dificuldades competitivas do país e das empresas.

Os impactes destes factores no emprego são manifestos, como veremos na secção seguinte, quer relacionados com as dificuldades de sustentação das empresas, quer no que concerne à atracção, ou preservação, de investimento estrangeiro. $\mathrm{O}$ aumento das falências e a deslocalização de empresas,

\footnotetext{
${ }_{3}$ O valor apresentado, no final de Março (2011), pelo Instituto Nacional de Estatística, de 8,6\%, foi corrigido na sequência do pedido de resgate financeiro à União Europeia e ao Fundo Monetário Internacional, para 9,1\%, devido ao enquadramento de contratos envolvendo parcerias público-privadas (PPP).

${ }^{4}$ Embora o desenvolvimento do sector das energias renováveis seja de salientar no contexto português como um dos mais elevados da União Europeia.
} 
o incremento actual da emigração, sobretudo de populações qualificadas, o desemprego e a precarização do emprego são assim as pontas do iceberg de um problema profundo de inoperância de uma gestão eficaz, estratégica e equitativa na sociedade portuguesa.

O Brasil, por seu turno, integrando o grupo dos chamados países emergentes (BRICs) tem vindo a demonstrar, nos últimos anos, capacidade para responder aos apelos de um mundo globalizado e aos sistemas de concorrência internacional.

No que diz respeito ao aspecto estritamente económico o optimismo é justificado. A economia tem demonstrado, há pelo menos uma década, um verdadeiro "espectáculo do crescimento económico", tal como foi expresso pela equipa do governo de Luiz Inácio da Silva, comparável apenas ao "milagre económico" da década de 1970. Na verdade, o Brasil, entre 2004 e 2008, cresceu a uma taxa média de 4,8\% e "após curto período de baixo dinamismo decorrente da crise mundial, a economia mostrou fôlego redobrado em 2010" (IPEA, Abril 2011:39).

No início da década de noventa, o governo Collor de Mello procurou implementar uma política económica e uma política externa que seguiam de perto as recomendações e directrizes do chamado Consenso de Washington, nomeadamente no que diz respeito a privatizações e liberalização económica, tanto no domínio dos fluxos de capitais, como dos fluxos de mercadorias.

O estudo de Mattoso (2001: 30), fazendo um balanço do processo de desenvolvimento brasileiro nos anos noventa, concluiu que a abertura comercial indiscriminada, a ausência de políticas industriais e agrícolas, a sobrevalorização do real e os elevados juros introduziram um freio ao crescimento do conjunto da economia e uma clara desvantagem da produção doméstica face à concorrência internacional. A reacção das empresas, dada a menor competitividade diante dos concorrentes externos, foi imediata: aceleraram a terceirização de actividades, abandonaram linhas de produtos, fecharam unidades, racionalizaram a produção, importaram máquinas e equipamentos, implementaram parcerias, fusões ou transferência de controlo accionário e reduziram os custos, sobretudo da mão-de-obra.

Com a ascensão de Lula da Silva à Presidência da República, em 2002, a política neoliberal manifestar-se-á principalmente em duas frentes: em primeiro lugar pela manutenção da arquitectura macroeconómica dos governos anteriores, principalmente no que respeita à política de criação de superavits primários e à política de juros elevados no quadro de uma obsessão pela estabilidade monetária. Em segundo lugar, pelo combate à 
fome e à miséria e pelo aprofundamento de políticas sociais de tipo focalizado, como o ProUni e o Programa Bolsa Família.5

Neste contexto, os juros elevados, em relação ao resto do mundo, e a estabilidade da moeda, têm provocado um influxo de capitais internacionais para o Brasil, tanto ao nível do investimento, como de capitais especulativos. A balança comercial tem apresentado superavits ao longo da década actual, principalmente em função da crescente procura de commodities por parte dos Estados Unidos e principalmente da China. Com efeito, estudos recentes (Pochmann, 2001; Murray, 2006) destacam as novas oportunidades para as empresas, potenciadas pela divisão internacional do trabalho, e que tendem a beneficiar as economias emergentes, nomeadamente a China, a Índia e o Brasil.

\section{Configurações do (des)emprego em Portugal e no Brasil}

O paradigma do trabalho encontra-se na actualidade sujeito a profundas transformações (Wallerstein, 1991; Schnapper, 1998; Sennett, 2001), que tendem a produzir dinâmicas complexas, disseminadas e, em grande medida, imprevisíveis, de vulnerabilização das condições de vida dos trabalhadores e de novas formas de pobreza. ${ }^{6}$ Com efeito, a crise do modelo de produção fordista evidencia-se de forma inequívoca em quase todos os países do mundo e o emprego precário e o desemprego parecem inscrever-se como marcas estruturais das sociedades contemporâneas, ${ }^{7}$ obrigando à interrogação sobre a genealogia e os impactes, individuais e colectivos, dos processos em curso.

\footnotetext{
${ }^{5}$ Genericamente, o ProUni é um programa federal focalizado que procura incluir estudantes pobres e negros no ensino de nível superior com a oferta de bolsas integrais e parciais no ensino superior privado. Já o programa Bolsa Família prevê a dotação de uma quantia em dinheiro (até ao máximo de 200,00 reais) para famílias carentes com renda inferior à linha da pobreza, condicionada à manutenção dos filhos na escola pública e à regularidade na vacinação das crianças. ${ }^{6}$ A centralidade deste debate decorre, desde logo, da importância assumida pelo trabalho assalariado como mecanismo de integração e de reconhecimento social, e mesmo moral, no âmago dos processos de coesão social. Como evidencia Schnapper (1998: 15), "se hoje devemos repensar o estatuto do trabalho, devemos fazê-lo sem negligenciar este elo original, que continua a ser fundamental, entre o trabalho produtivo e a cidadania. $\mathrm{O}$ cidadão moderno adquire a sua dignidade trabalhando". Nesta perspectiva, reflectir sobre os fundamentos e dimensões do trabalho constitui-se como um ponto de partida incontornável para a determinação dos fins colectivos a efectivar, sobre a relação entre os ditos fins e as opções económicas e sobre os papéis a desempenhar pelos cidadãos. Em suma, sobre as bases de um (novo) contrato social, reinterpretado à luz dos atuais dados económicos e políticos em sociedades globais.

${ }^{7}$ O Relatório da OIT sobre Tendências Mundiais do Emprego (ILO, 2009) identifica 212 milhões de desempregados no mundo (aumento sem precedentes de 34 milhões de pessoas por referência a 2007 antes da crise global), destacando o aumento previsível de 3 milhões de desempregados, só no contexto da União Europeia (UE), no ano de 2010 (a taxa de desemprego na UE em 2009 situar-se-ia, de acordo com o mesmo Relatório, em 8,4\% contra 6\% em 2008 e 5,7\% em 2007).
} 
Um aspecto que nos parece constituir-se como particularmente relevante para a compreensão das dinâmicas actualmente em curso no mercado de trabalho relaciona-se com a passagem de uma lógica capitalista de homogeneização da mão-de-obra para a gestão diferenciada e multifocal da força de trabalho (Caire, 1982). Neste contexto, as formas atípicas de inserção profissional, não se constituindo como absolutamente inovadoras, adquirem hoje, no contexto da globalização, novas configurações e significados que tendem a transfigurar o mercado de trabalho (Leite, 2009).

Em primeiro lugar, nas últimas décadas, têm ocorrido mutações significativas nas configurações da força de trabalho. Entre os vários aspectos dessa mudança destacam-se duas tendências: a polarização entre trabalho qualificado e não qualificado (Sklair, 1991; Reich, 2001; Estanque, 2005) e a progressão do trabalhador qualificado para o trabalhador complexo.

O processo de reorganização económica, decorrente ou potenciado pela globalização, tende de facto a incrementar polarizações no mundo do trabalho e do emprego, que se repercutem necessariamente nos processos de inserção social e no nível de desigualdades socioeconómicas que caracterizam, quer a sociedade portuguesa, quer a sociedade brasileira. Assim, num dos pólos da equação verifica-se o incremento de situações diversas de precariedade (laboral e social) que, em última análise, penalizam sobretudo categorias populacionais mais vulneráveis, que não dominam a informação pertinente, que estão mais sujeitas a situações de exploração e submissão (como é o caso dos trabalhadores imigrantes ilegais) e que, como tal, possuem menores possibilidades de inverter ciclos de precarização e de resignação. No outro pólo, emerge uma "nova elite socioprofissional" (Estanque, 2005), qualificada e adaptável, que se move à escala global e que domina as competências e os fluxos informativos reticulares passíveis de preservar a sua operacionalidade e poder. Deste modo, como sublinha Estanque (2005), as desigualdades multiplicam-se e as distâncias socioespaciais tendem a aumentar.

No âmago desta discussão duas tendências de (re)configuração do mercado de trabalho merecem maior destaque, pela relevância que possuem nos dois contextos que ilustram a nossa reflexão, a informalização da força de trabalho e a precariedade.

De acordo com vários estudos, a informalidade não só se amplia com o desenvolvimento do capitalismo, contrariamente ao que era previsto (Tokman, 2004), como surge uma "nova informalidade" (Baltar e Deddeca, 1997; Noronha, 2003), que emerge no âmago da própria formalidade e se torna constitutiva da produção capitalista. Aqueles que Portes, Castells e Benton (1989) apelidam de "assalariados disfarçados" integram assim o 
"excedente de mão-de-obra que está disponível para responder às necessidades dos sectores mais modernos, permitindo diminuir os custos de trabalho" (Tokman, 2004: 200).

Em paralelo, a compreensão do conceito de trabalho precário pressupõe, não apenas a identificação das suas dimensões (Rodgers, 1989: 3) - grau de instabilidade; grau de controlo dos trabalhadores sobre as condições de trabalho; protecção (quer por via de legislação laboral, quer de contratos colectivo de trabalho) e rendimento - mas igualmente as formas complexas como as mesmas se combinam. As condições do mercado de trabalho, as mudanças nos modelos organizativos (por exemplo, a flexibilização, os contratos a prazo, a prestação de serviços, etc.), uma legislação laboral mais restritiva em termos de direitos dos trabalhadores e a orientação para a desregulação do mercado de trabalho (tendências hoje muito patentes na sociedade portuguesa), tendem a promover formas de trabalho precário, já não esporádicas e periféricas, mas estratégicas e centrais na lógica de dominação capitalista actual (Leite, 2009: 14). Aliás, como salientam Rodgers e Rodgers (1989), não se trata da emergência de um mercado dual. A realidade é mais complexa e disseminada a partir do momento em que certas formas de trabalho precário coexistem com modelos mais perenes na mesma empresa ou serviço.

O desemprego acresce e complexifica este cenário, contribuindo para processos profundos e multidimensionais de precarização das condições de vida de populações, cada vez mais aleatórias e heterogéneas.

O Relatório da Organização Internacional do Trabalho (ILO) sobre as Tendências Mundiais do Emprego (2009) destaca a elevação da taxa de desemprego na América Latina e Caribe para 8,2\% em 2009 contra $7 \%$ em 2008, o que corresponde a um aumento de cerca de 4 milhões de desempregados. O mesmo Relatório sublinha ainda a elevação nos níveis de trabalhadores em situação de pobreza extrema, de $7 \%$ em 2008 para $9,9 \%$ em 2009. Também no contexto da União Europeia (UE), se verifica, nas últimas duas décadas (de acordo com dados do Eurostat), um incremento do desemprego estrutural e persistente, correspondendo actualmente (Março de 2011) a uma taxa de cerca de $9,9 \%$ da população europeia em idade activa, contra $6 \%$ em $2008 .{ }^{8} \mathrm{O}$ desemprego na UE corresponde assim, desde 2007, a mais de $40 \%$ do desemprego global (ILO, 2009).

\footnotetext{
${ }^{8}$ Esta situação é actualmente tanto mais grave quanto a UE se confronta com a necessidade de equilíbrio das finanças públicas e de controlo da dívida em diversos países, nomeadamente Portugal, Espanha, Irlanda e Grécia, condicionando, entre outros aspectos, a amplitude e a preservação de apoios sociais e a consequente centralidade em mecanismos de governabilidade e de estabilização financeira.
} 
Em termos mais específicos, Portugal possui, no momento presente, de acordo com os últimos dados divulgados pelo INE, referentes ao primeiro trimestre de 2011, uma taxa oficial de desemprego de 12,4\% (correspondendo a cerca de 688,9 mil portugueses sem trabalho, dos quais 126 mil são jovens), ${ }^{9}$ a mais alta da sua História e a quarta mais elevada de 21 países da UE com informação apurada no período em referência (Eurostat, Abril 2011). Se compararmos a última década (tabela I) verifica-se que em 2010 a taxa de desemprego $(11,2 \%)$ corresponde a mais do dobro da verificada em $2001(4,1 \%)$, sendo que nos últimos quatro anos esta taxa se situa acima da taxa média da UE.

TABELA I - Taxa de desemprego da população portuguesa em comparação com a União Europeia a 27

\begin{tabular}{|c|c|c|c|c|c|c|c|c|c|c|c|}
\hline Ano & $\mathbf{2 0 0 1}$ & $\mathbf{2 0 0 2}$ & $\mathbf{2 0 0 3}$ & $\mathbf{2 0 0 4}$ & $\mathbf{2 0 0 5}$ & $\mathbf{2 0 0 6}$ & $\mathbf{2 0 0 7}$ & $\mathbf{2 0 0 8}$ & $\mathbf{2 0 0 9}$ & $\begin{array}{c}\mathbf{2 0 1 0} \\
\text { Dez. }\end{array}$ & $\begin{array}{c}\mathbf{2 0 1 1} \\
\text { Abril }\end{array}$ \\
\hline Portugal & 4,1 & 5,1 & 6,4 & 6,7 & 7,7 & 7,8 & 8,1 & 7,7 & 9,6 & 11,2 & 12,6 \\
\hline UE & 8,5 & 8,9 & 9,0 & 9,1 & 8,9 & 8,2 & 7,1 & 7,0 & 8,9 & 9,5 & 9,4 \\
\hline
\end{tabular}

Fonte: Eurostat, EU LSF (2010); Newsrelease Euroindicators (Abril 2011)

O desemprego, atingindo populações heterogéneas, constitui-se assim como um dos problemas mais graves da sociedade portuguesa contemporânea, sobretudo se considerarmos, por um lado, as dificuldades estruturais de recuperação económica e de resposta adequada aos fluxos e pressões globais que já salientámos, e que se manifestam por exemplo na elevada percentagem de desempregados de longa e de muito longa duração, ${ }^{10} \mathrm{e}$ por outro, a descoincidência acrescida entre necessidades sociais e apoios disponibilizados (estima-se que, em Dezembro de 2010, mais de $45 \%$ das pessoas sem trabalho não tinham qualquer apoio social).

Verifica-se igualmente, no contexto português actual, um agravamento da precarização do emprego de 2009 para 2010. De acordo com os dados mais recentes divulgados pelo Eurostat (tabela II), Portugal é o terceiro

\footnotetext{
9 Taxa de desemprego calculada de acordo com uma nova forma de cálculo do número de desempregados através de questionários telefónicos e da utilização de novas tecnologias. No cenário de manutenção do processo de cálculo anterior estima-se que a taxa se situaria em 11,4\% (INE, 2011). Entretanto, os últimos números divulgados pelo Eurostat, referentes a Abril de 2011 (Newsrelease Euroindicators, seasonally adjusted unemployment rates, Abril 2011), situam a referida taxa já em $12,6 \%$.

${ }^{10}$ De acordo com os dados do $1 .^{\circ}$ trimestre de 2011 (INE, 2011), o número de desempregados de longa duração (ou seja, à procura de emprego há 12 ou mais meses) correspondia a $53 \%$ (dos quais $29,3 \%$ procuravam emprego há mais de dois anos) da população desempregada total.
} 
país da União Europeia a 27 (a seguir à Polónia e à Espanha) com maior nível de precariedade. Considerando um dos critérios associados à definição de trabalho precário, um em cada cinco empregados tinha, em 2010, um emprego temporário. ${ }^{11}$

TABELA II - Evolução dos contratos a termo em Portugal (\% do emprego total) em comparação com a União Europeia

\begin{tabular}{|c|c|c|c|c|c|c|c|c|c|c|}
\hline Ano & $\mathbf{2 0 0 1}$ & $\mathbf{2 0 0 2}$ & $\mathbf{2 0 0 3}$ & $\mathbf{2 0 0 4}$ & $\mathbf{2 0 0 5}$ & $\mathbf{2 0 0 6}$ & $\mathbf{2 0 0 7}$ & $\mathbf{2 0 0 8}$ & $\mathbf{2 0 0 9}$ & $\mathbf{2 0 1 0}$ \\
\hline Portugal & 20,3 & 21,5 & 20,6 & 19,8 & 19,5 & 20,6 & 22,4 & 22,8 & 22 & 23 \\
\hline EU (27) & 12,4 & 12,3 & 12,7 & 13,3 & 14,0 & 14,5 & 14,6 & 14,2 & 13,6 & 14 \\
\hline
\end{tabular}

Fonte: Eurostat, EU LFS (Employees with a contract of limited duration, annual average), 2010.

De acordo com os dados entretanto divulgados pelo INE, referentes apenas ao $1 .^{\circ}$ trimestre de $2011,77,9 \%$ dos trabalhadores por conta de outrem possuía um contrato de trabalho sem termo (com maior proporção de homens), $18,7 \%$ um contrato com termo e 3,4\% encontravam-se em outra situação contratual.

Por outro lado, intensificou-se o número de trabalhadores, sobretudo jovens, ${ }^{12}$ que exercem funções (muitas vezes de cariz central e estratégico, os "falsos recibos verdes") em regime de "trabalho independente", o que não deixa de se constituir como uma forma de precarização e de neutralização da segurança essencial à formulação de um projecto de vida estruturado. Estes factores, em paralelo com uma economia informal forte, com a exploração de uma enorme massa de imigrantes sem documentação (sobretudo provenientes do Brasil e dos países do Leste europeu) e situações de "nova

\footnotetext{
11 "The concepts of 'temporary employment' and 'work contract of limited duration' (...) describe situations which, in different institutional contexts, may be considered similar. Employees with a limited duration job/contract are employees whose main job will terminate either after a period fixed in advance, or after a period not known in advance, but nevertheless defined by objective criteria, such as the completion of an assignment or the period of absence of an employee temporarily replaced. The following belong to these categories: Persons with seasonal employment, persons engaged by an agency or employment exchange and hired to a third party to perform a specific task (unless there is a written work contract of unlimited duration with the agency or employment exchange), and persons with specific training contracts". http://epp.eurostat.ec.europa.eu/portal/ page/portal/employment_unemployment_lfs/methodology/definitions/. Consultado em Abril 2011. ${ }_{12}$ De acordo com o Relatório da Comissão Europeia Employment in Europe 2010, são os jovens (15-24 anos) o grupo proporcionalmente mais afectado pela contracção do emprego com o surgimento da crise internacional (decréscimo de 11,4\%). Verificam-se igualmente grandes taxas de emprego temporário nesta população: em 2008, 40\% dos empregados europeus com idades compreendidas entre os 15 e os 24 anos possuía uma vinculação temporária. Dados divulgados pelo INE (2010) sublinham também que é entre a população jovem portuguesa com formação superior que os contratos a termo e os recibos verdes mais têm crescido (cerca de $129 \%$ na última década).
} 
escravatura" e tráfico de mão-de-obra (imigrante e emigrante), constituem-se como reconfigurações do emprego, potenciadas pela globalização, e que tendem a conduzir e a enquadrar em novas situações de pobreza sectores populacionais heterogéneos e vulnerabilizados (Estanque, 2005).

Em paralelo, a dimensão da protecção social em Portugal nunca foi suficientemente forte para compensar todos os problemas estruturais de uma sociedade afastada dos pressupostos de desenvolvimento durante quase meio século de ditadura (1933-1974). Como evidencia Hespanha (2007: 24), em Portugal

a lógica da condição salarial não foi inteiramente assimilada, nem as políticas passivas, longe dos níveis atingidos na generalidade dos parceiros europeus, cobrem as necessidades sociais decorrentes da perda do emprego. De facto, a estruturação do mercado de trabalho nunca generalizou a relação salarial relativamente estável como forma dominante de uso do trabalho, tal como aconteceu nos países centrais.

As actuais políticas sociais de incentivo ao emprego e de controlo do desemprego em Portugal assumem essencialmente uma configuração de activação que, se por um lado coloca em evidência as potencialidades, capacidades de adaptação e percursos de aprendizagem dos indivíduos para a sua reintegração socioprofissional, não deixa de evidenciar, no reverso da medalha, a progressiva retracção do Estado, num contexto de pressão financeira internacional, no domínio dos apoios sociais e na criação de respostas e oportunidades de cariz estruturante. Ora, a tendência para a implementação de políticas que incidem mais sobre os efeitos do que sobre as causas dos problemas sociais não permite criar condições para a transformação efectiva, perene e sustentada das condições de vida das populações em situação de maior vulnerabilidade socioeconómica. Com efeito, embora alguns estudos revelem a importância de políticas sociais de combate à pobreza, assentes nomeadamente em provas de condição de recursos, para a diminuição dos indicadores de pobreza absoluta, não deixam de evidenciar igualmente a sua insuficiência para a mudança em profundidade dos factores e dinâmicas na sua origem (Rodrigues, 2011).

No que diz respeito ao contexto brasileiro, o mercado de trabalho, que desde o início do processo de industrialização intensiva (anos 50) se caracterizou por um elevado grau de informalidade (trabalho por conta própria, trabalho não registado ou micro negócios) e pouca estruturação (Leite, 2009), adquiriu um novo perfil a partir do final dos anos oitenta. O novo cenário foi redefinido, em primeiro lugar, em função das mudanças institucionais produzidas pela abertura política, principalmente decorrente da nova 
Constituição de 1988 e, em segundo lugar, pelo ambiente de crise económica estrutural que se consubstanciou numa persistente estagnação do crescimento económico. A este quadro vieram somar-se as novas modalidades de política económica de tipo neoliberal, que foram adoptadas no Brasil a partir da ascensão ao poder do presidente Fernando Collor de Melo, em 1990.

As referidas políticas, principalmente no que diz respeito à abertura económica, foram acompanhadas de várias formas de flexibilização da estrutura económica e social e de altas taxas de juros, exercendo consequentemente pressões substanciais no nível e no perfil do emprego. O resultado bastante visível foi uma reestruturação (ou desestruturação) profunda do mercado de trabalho. Estas transformações associadas à abertura económica, a inovações tecnológicas, à reestruturação industrial, à terceirização da economia e à flexibilização produtiva, trouxeram uma novidade na estrutura económica capitalista, cujo epicentro está na maior racionalização na criação de empregos, dada a nova estrutura tecnológica flexível do capitalismo global. Neste contexto, vários estudos têm procurado reflectir sobre a reconfiguração de práticas anteriores (trabalho ao domicílio, trabalho ambulante, trabalho a tempo parcial, etc.) em novos contextos e sobretudo como é que se misturam, no mercado de trabalho, o formal e o informal, ${ }^{13}$ o regular e o atípico (Lavinas et al., 1998; Lima, 2008).

O trabalho informal passa também a figurar no contexto da economia urbana como sendo de grande importância para a manutenção de uma certa ordem social, que poderia vir a ser desfeita pela pressão dos que se encontram excluídos do mercado de trabalho formal, e que sem a oportunidade de encontrar emprego poderiam rebelar-se. $\mathrm{O}$ crescimento populacional e a complexificação das relações sociais e económicas no meio urbano levam ao surgimento ou à possibilidade de desempenhar funções que, embora pudessem já existir, se expandem e diversificam, constituindo-se, como já referimos, como elementos integrantes de uma nova configuração do mercado de trabalho em sociedades globalizadas. $\mathrm{O}$ trabalho ambulante, por exemplo, sempre tendo existido no Brasil como forma de sobrevivência para populações vulneráveis e/ou afastadas do trabalho assalariado, adquire hoje novas configurações associadas à lógica capitalista (novos produtos, transferência da actividade para shoppings, etc.): "A antiga informalidade

\footnotetext{
${ }_{13}$ De acordo com Gonçalves e Thomaz (2002: 4), o sector informal "estaria ocupando 'as franjas do mercado' os espaços ainda não preenchidos ou já abandonados pela produção capitalista, concentrando-se, em última análise, nas actividades que inibem um processo sistemático de acumulação do capital". Estas "frestas" seriam então ocupadas pelos trabalhadores desempregados e que, sem condições económicas, teriam no distanciamento da formalização um elemento importante para a manutenção da realização de determinadas actividades que, assim caracterizadas, comporiam o sector informal.
} 
é assim redefinida para uma situação de trabalho na qual a característica mais importante é a individualização e a subjectivação dos controlos [...] caracterizando a institucionalização da precariedade das relações produtivas e da protecção social" (Neves et al., 2006, apud Leite, 2009: 24).

$\mathrm{Na}$ passagem do milénio, os dados do IBGE $(2010)^{14}$ demonstram que $56 \%$ dos trabalhadores estavam na informalidade. Segundo os mesmos dados, no início da primeira década, inicia-se uma tendência de descida: a taxa de informalidade em 2001 é de 55,2\%, em 2002 de 55,3\%, em 2008 de $49,2 \%$, chegando em 2009 , último dado disponível, a 48,7\%, em consonância com a melhoria de outros indicadores macroeconómicos do período.

No que diz respeito aos dados do desemprego verifica-se a mesma tendência de descida ao longo da última década (tabela III).

TABELA III - Evolução da taxa de desemprego no Brasil

\begin{tabular}{|c|c|c|c|c|c|c|c|c|c|}
\hline Ano & $\mathbf{2 0 0 2}$ & $\mathbf{2 0 0 3}$ & $\mathbf{2 0 0 4}$ & $\mathbf{2 0 0 5}$ & $\mathbf{2 0 0 6}$ & $\mathbf{2 0 0 7}$ & $\mathbf{2 0 0 8}$ & $\mathbf{2 0 0 9}$ & $\mathbf{2 0 1 0}$ \\
\hline Taxa de desemprego & 12,6 & 12,3 & 11,4 & 9,8 & 9,9 & 9,3 & 7,8 & 8,1 & 6,7 \\
\hline
\end{tabular}

Fonte: IBGE-Instituto Brasileiro de Geografia e Estatística (Junho 2011)

Esta tendência, que se vem verificando desde o final da década de 90, associada à recuperação do emprego industrial e à inversão nos processos de desestruturação do mercado de trabalho (Pochmann et al., 2007), tem conduzido, como os dados parecem revelar, à diminuição das taxas de desemprego e de trabalho precário (Leite, 2009). Esta evolução fica a dever-se não somente às oportunidades acrescidas propiciadas pela globalização económica, mas também a um conjunto de esforços legislativos e institucionais de regulação laboral (Pochmann et al., 2007).

\section{Globalização, emprego e (nova) pobreza nas sociedades portuguesa e brasileira}

As conexões entre as configurações actuais do capitalismo globalizado e a pobreza no mundo têm sido analisadas por diversos autores (Bourdieu, 1993; Castel, 1995; Chomsky, 1996), colocando em destaque os mecanismos excludentes de mercados de trabalho cada vez mais precarizados.

\footnotetext{
${ }^{14}$ Grau de informalidade (\%): uma das três diferentes definições do grau de informalidade oferecidas no Ipeadata com base na Pesquisa Nacional por Amostra de Domicílios (Pnad) do IBGE, esta taxa corresponde ao resultado da seguinte divisão: (empregados sem carteira + trabalhadores por conta própria) / (trabalhadores protegidos + empregados sem carteira + trabalhadores por conta própria). Elaboração: Disoc/Ipea. Actualizado em: 16/02/2011. http://www.ipeadata.gov. br/Default.aspx. Acesso em Junho 2011.
} 
No contexto das mudanças estruturais em curso, decorrentes ou potenciadas pelo processo de globalização económica, desenvolve-se hoje um amplo debate, na Europa e na América Latina, sobre o fenómeno da pobreza, da precariedade, da exclusão e da (des)integração social. Neste contexto, a utilização do conceito de nova pobreza, que na verdade emerge nas últimas duas décadas do século passado (Candel, 1988; Room, 1990; Saraceno, 1990; Paugam, 1996), pretende traduzir a realidade dos supranumerários (Castel, 1995) e de todos aqueles cujas expectativas, processos e pressupostos de relação com os mercados de trabalho e de consumo se encontram colocados em causa, ou estão de tal forma fragilizados que não asseguram um sentido de pertença e de participação, essencial à plena fruição de cidadania $\mathrm{e}$ integração social. É assim possível enquadrar neste conceito categorias tão heterogéneas como as famílias sobreendividadas, os working poor, os desempregados de longa duração ou os jovens à procura do primeiro emprego (Wanderley, 2001: 19). Segundo Jordi Estivill (2003: 22),

talvez as figuras mais representativas do que se chama «nova pobreza» são os trabalhadores qualificados expulsos do seu trabalho devido às reconversões industriais e às alterações tecnológicas; alguns pequenos empresários, comerciantes, artesãos e profissionais sem possibilidade de adaptação; pessoas, especialmente mulheres, que tendo responsabilidades familiares não podem obter trabalho ou que o perdem; pessoas que se endividam para além das suas posses. Não se trata de indivíduos inconformistas como no caso anterior; ou inaptos para o trabalho e sem relações sociais; são, sim, pessoas com dificuldades relacionadas com o emprego e com os seus rendimentos.

De forma consequente, para Graham Room (1990) os novos pobres são aqueles que estão impedidos de concretizarem os seus direitos sociais. A exclusão social ganha assim uma dimensão considerável, colocando em evidência o conjunto de contradições e fracturas que caracterizam as sociedades contemporâneas ocidentais (Paugam, 1996). Tais contradições, embora com feições diferenciadas, atingem estruturalmente sociedades com níveis de desenvolvimento distintos. Com efeito, a nova pobreza não é apenas um fenómeno que atinge os países pobres: "ao contrário, ela sinaliza o destino excludente de parcelas majoritárias da população mundial, seja pelas restrições impostas pelas transformações do mundo do trabalho, seja pelas desigualdades absurdas de qualidade de vida" (Wanderley, 2001: 16). No contexto português, o actual incremento e persistência das situações de desemprego e de sobreendividamento das famílias, a par da ampliação e complexificação dos fenómenos de atipicidade laboral, potenciados, como já vimos, pela fragilidade de uma economia incapaz de responder da 
melhor forma às pressões globais, coloca hoje o país face a uma situação de grave crise social.

Um estudo recente sobre pobreza e desemprego na região centro de Portugal, (Hespanha, 2007: 20) afirma que, embora o desemprego, o "mau emprego", ${ }^{15}$ a pobreza e a exclusão social "não se sobreponham necessariamente, a verdade é que podem encontrar-se, tocar-se, cruzar-se. As fronteiras entre elas não são estanques. Ao contrário, são porosas e, através de redes complexas de interdependências, permitem múltiplos pontos de contacto". A pressão exercida sobre os mais vulneráveis (os pobres, os idosos, os menos qualificados, os jovens, as mulheres, os deficientes, os imigrantes), as inversões em percursos de integração socioeconómica decorrentes de "ajustamentos" no mercado de trabalho (encerramento de empresas, deslocalizações, despedimentos, desregulamentação de direitos laborais), os baixos salários ${ }^{16}$ e as restrições em termos de apoios sociais (com critérios cada vez mais selectivo e pouco adaptados às novas situações, mais perenes e complexas), remetem para situações de pobreza (muitas vezes velada e gerida em silêncios tácitos) grupos cada vez mais alargados e heterogéneos de populações, quer anteriormente inseridas socioprofissionalmente, quer trabalhadores com baixos salários e muitas vezes desprotegidos socialmente.

A nova pobreza está assim intimamente associada às mudanças potenciadas pelo novo padrão de produção no quadro da globalização capitalista, atingindo também a classe trabalhadora activa via mudanças no perfil do mercado de trabalho. As primeiras grandes reestruturações industriais e a diminuição consequente do poder de compra dos indivíduos e das famílias atingidas pelo desemprego, a invisibilidade e falta de protecção inerente ao sector informal e a inadequação ou ausência de "capital cultural e simbólico" julgado pertinente face às exigências globais, também têm fortes impactes nas novas formas de pobreza.

Os estudos de avaliação dos impactes do Rendimento Mínimo Garantido (Comissão Nacional do Rendimento Mínimo, 2002) no combate à pobreza e exclusão social em Portugal destacavam já a relação entre o perfil do desempregado de longa duração e a pobreza. ${ }^{17}$ As causalidades identificadas foram,

\footnotetext{
${ }^{15}$ Conceito que agrega todas as formas de trabalho de carácter atípico, mal remunerado, geralmente de curta duração e sem perspectivas de progressão em termos pessoais e de carreira.

${ }^{16}$ De acordo com dados do Eurostat (Fevereiro de 2011), o salário mínimo bruto (485 euros) e o salário médio bruto (1247 euros) português situa-se a meio da tabela em comparação com os valores da zona euro. As desigualdades salariais são, no entanto, muito acentuadas no contexto português (Rodrigues, 2011).

${ }_{17}$ O estudo conduzido por Bruto da Costa e colaboradores, de 1995 a 2000, evidencia que cerca de metade das famílias portuguesas vive numa situação vulnerável à pobreza, mais grave que uma situação de "risco de pobreza", uma vez que a pobreza foi de facto vivenciada em pelo menos um
} 
em primeiro lugar, de carácter estrutural, quer ao nível de funcionamento do mercado de trabalho, quer ao nível das assimetrias regionais na oferta de emprego. A estas acresciam causalidades associadas aos baixos salários e a factores de carácter individual, nomeadamente baixas condições de empregabilidade ou expectativas dissonantes.

De acordo com os dados do Panorama de Indicadores Sociais 2011, da OCDE (2011), Portugal registou apesar de tudo, nas duas últimas décadas, uma evolução positiva na diminuição da taxa de pobreza situada, em 2008, em $17,9 \%$ (embora as estimativas actuais apontem para um novo retrocesso após essa data). Estes dados colocam em evidência a importância das transferências sociais (nomeadamente no caso da diminuição da pobreza entre os idosos), sem as quais a incidência da pobreza passaria para $24,3 \%$ (INE, 2010). O rendimento social de inserção, o complemento solidário para idosos e a elevação (embora ténue) do salário mínimo e das pensões mais baixas tiveram a este respeito um contributo efectivo (Rodrigues, 2011).

No entanto, é também importante aprofundar os estudos e ponderar a efectividade das políticas sociais actuais de combate à pobreza em termos de transformação das condições de vida das pessoas e da redução das desigualdades (Rodrigues, 2011). Na verdade, os efeitos parecem esgotar-se "na correcção das assimetrias da parte inferior da distribuição do rendimento, deixando de fora as que ocorrem na parte superior da distribuição" (Rodrigues, 2011: 54). Além disso, demonstram ser pouco adequadas para responder às situações de precariedade e nova pobreza que exigem reformas e medidas multidimensionais, integradas e estruturais.

A análise profunda das situações actuais implica realçar que Portugal continua abaixo da média dos países da OCDE, em termos de rendimento médio disponível por família, e possui uma maior percentagem de pessoas que vivem com menos de metade do rendimento médio familiar (13,6 para Portugal e 11,5 para os países da OCDE). As possibilidades de recuperação deste hiato são particularmente agravadas pela actual crise económico-financeira e pelas exigências de controlo das contas públicas portuguesas, num quadro de compromissos europeus e internacionais de estabilidade e crescimento.

A globalização manifesta-se assim em Portugal, na actualidade, sobretudo sob o enfoque da competição económica, que tende a subordinar as políticas públicas a lógicas orçamentais. A crise social, profunda e em crescendo, e

ano. A identificação das situações de pobreza centrou-se no nível de rendimentos anuais, pelo que não se trata de uma ocorrência momentânea, nem tão pouco marginal na sociedade portuguesa. É antes um problema social extenso e persistente (Costa, 2008: 185). 
a mobilização, que começa a incrementar-se (promovida não apenas pelos sindicatos, mas também por grupos da sociedade civil como os "jovens precários"), fruto da maior consciencialização das desigualdades ilegítimas e de ruptura de expectativas, colocam Portugal face a um dos maiores desafios da sua história recente: a reconstrução de um sentido de justiça social e de reconhecimento que não seja aglutinado por lógicas de eficiência e eficácia económica apresentadas de forma (perversamente) autolegitimante.

No que diz respeito ao Brasil, embora seja uma das economias que mais cresceu no período recente, continua a abarcar um dos maiores índices de pobreza e de desigualdade de rendimentos do mundo. Segundo dados do IPEA (2010) persistem 43 milhões de brasileiros vivendo abaixo da linha de pobreza; porém, a recuperação face a dados de um passado ainda relativamente recente comprovam uma tendência de queda destes indicadores muito assinalável (em 1983 um em cada dois brasileiros correspondia aos critérios de classificação como pobre; em 2010 a proporção passa a ser de um em cada quatro). O mesmo organismo cita como factores explicativos da descida dos valores da pobreza as políticas públicas de distribuição de renda, a elevação do valor real do salário mínimo e a constituição de uma rede de garantia de renda aos pobres.

A compreensão da pobreza no Brasil possui na verdade raízes históricas complexas. Com efeito, na origem dos trabalhadores pobres e despossuídos do século XXI há uma longa trajectória que tem início na população escrava e nos trabalhadores da economia de subsistência, que sobreviveu à abolição da escravatura. De acordo com o estudo de Delgado (2004: 16),

a sociedade que se forja no Brasil depois da abolição carrega no seu âmago duas questões mal resolvidas do século anterior: as relações agrárias arbitradas pelo patriciado rural, mediante a lei de Terras (1850), profundamente restritiva ao desenvolvimento da chamada agricultura familiar; e uma lei de libertação dos escravos que nada regula sobre as condições de inserção dos ex-escravos na economia e na sociedade pós-abolição. [...] Tal sociedade de grandes proprietários de terra e de poucos homens assimilados ao chamado mercado de trabalho inaugurou o século XX impregnada pela desigualdade de oportunidades e pelas condições de reprodução humana impostas à esmagadora maioria dos agricultores não proprietários e trabalhadores urbanos não inseridos na economia mercantil da época.

Este contexto histórico remete-nos para a compreensão das especificidades da pobreza no Brasil. A miséria e a pobreza tradicional, sobretudo inscrita nas zonas rurais e no interior, diminuem de facto com os programas desenvolvidos nos últimos anos de combate à fome e à privação. O programa 
Bolsa-Família tem tido a este nível impactes relevantes. No entanto, a nova pobreza, emergente sobretudo nos contextos urbanos, sendo mais complexa e multidimensional, não é atingida por medidas focalizadas, como vários analistas brasileiros e internacionais têm acentuado. Por exemplo, o trabalho das crianças na venda de doces ("balas") nas ruas das cidades é mais "compensador" economicamente para as famílias do que a ida à escola e a recepção consequente do Bolsa-Família.

Um aspecto relevante para a compreensão da nova pobreza no Brasil relaciona-se com a educação e as procuras do mercado de emprego. Com efeito, o desenvolvimento da economia, à escala global, aumenta a exigência dos empregadores relativamente ao nível de sofisticação e de especialização dos conhecimentos dos trabalhadores. O desenvolvimento económico e tecnológico, que caracteriza actualmente o Brasil, potenciado pela globalização, tende assim, no reverso da medalha, a produzir novas dinâmicas de exclusão e, como tal, a potenciar processos de precarização laboral e sobretudo social de muitas centenas de trabalhadores.

A questão mais dramática, quer em Portugal, quer no Brasil, apesar da melhoria dos indicadores nos dois casos, continua a ser o nível de desigualdade, obrigando necessariamente ao alargamento do prisma analítico às condições - económicas, sociais e políticas - de cariz estrutural.

Ao analisar os dados do IPEAdata, de 1999 a 2009, verifica-se que nesta última década houve uma pequena melhoria nos indicadores de concentração e desigualdade de rendimento no Brasil. O índice de Gini passou de 0,594 em 1999 para 0,543 em 2009. Ainda assim, apesar de tais dados de cariz positivo, não se evidenciam mudanças estruturais no perfil da distribuição de rendimentos e na redução das desigualdades sociais no país. Os patamares de pobreza e desigualdade ainda estão distantes dos desejáveis para a promoção da justiça social e do bem-estar. A despeito da descida dos indicadores de pobreza, estes demonstram que não houve mudanças estruturais na distribuição da renda pois as políticas sociais em prática caracterizam-se por não afectar a estrutura da pirâmide social. Neste sentido, uma sociedade em que $1 \%$ dos mais ricos se apropriava, em 1999, de $13,24 \%$ da renda e, em 2009, de 12,11\%, ainda é uma sociedade extremamente injusta do ponto de vista social (IPEA, 2010).

Em Portugal, apesar do índice de Gini também ter vindo a diminuir nas últimas décadas (actualmente corresponde a 0,354), o país continua a ser o mais desigual da União Europeia a 15 países (e o terceiro na UE a 27). Trata-se, neste caso, essencialmente de uma desigualdade salarial acentuada (os $5 \%$ mais ricos ganham 18 vezes mais que os $5 \%$ mais pobres) (Rodrigues, 2011). 


\section{Considerações finais}

A necessária análise substancial das efectivas condições de vida e de trabalho das populações, que a mera dimensão estatística tende a ocultar, parece-nos pois crucial para uma reflexão profunda sobre os reais impactes dos modelos económicos vigentes na produção de lógicas (profundas e mais ou menos consentidas e disseminadas) de ocultação e/ou de reprodução de desigualdades.

O caso português e o caso brasileiro evidenciam os dois lados da moeda desta reflexão. O caso português, elucidativo da profunda desagregação social e económica decorrente de processos globais de aglutinação, de retóricas economicistas e de incapacidade de afirmação à escala mundial, e mesmo europeia; o caso brasileiro, elucidativo do "milagre económico", estatisticamente comprovado, porém ainda não substancial e plenamente consolidado num prisma de desenvolvimento multidimensional.

$\mathrm{Na}$ verdade, os dados referentes ao contexto brasileiro comprovam a importância do crescimento do emprego, acompanhado de regulação estatal das formas "selvagens de terceirização" e informalidade (Pochmann et al., 2007: 6). A tendência de diminuição das taxas de desemprego e de precarização do trabalho, a par de um crescimento económico (em termos gerais) regular e de uma maior aposta na educação e na investigação científica, permitem caracterizar o Brasil contemporâneo como um dos países que melhor se tem adaptado aos desafios globais. Apesar de manter fortes índices de pobreza e de desigualdade, a par de um mercado de emprego ainda largamente desestruturado (que ocupa aproximadamente $40 \%$ da população economicamente activa), as tendências de melhoria, sobretudo ao longo da última década, são inequívocas e permitem afirmar que a "precarização e a informalização não são tendências inexoráveis, mas que podem ser controladas a partir de políticas orientadas para o crescimento da economia e, em particular, do sector industrial" (Leite, 2009: 26).

Portugal, por seu turno, encontra-se em trajectória descendente em termos de desenvolvimento económico, como confirmam diversos indicadores. O desemprego aumenta a par do incremento do trabalho precário, condicionando, de forma negativa, as vivências concretas de largas centenas de pessoas, com perfis e trajectória de vida diferenciadas. A promoção do emprego e a afirmação do país no contexto global constituem-se neste contexto como condições incontornáveis para a minimização dos processos de precarização laboral e social de largos extractos populacionais.

A nova pobreza tende a constituir-se como dimensão estruturante das sociedades globais e, em grande medida, produto dos impactes produzidos no mercado de trabalho. Os desafios que a este nível se colocam não são muito diferentes nos dois contextos considerados. 
A diminuição das estatísticas da pobreza na actualidade, tanto na sociedade portuguesa como na brasileira, coloca de facto em destaque diversos elementos. Em primeiro lugar evidencia a importância das transferências sociais para responder às formas de pobreza tradicionais, mas também coloca em relevo a importância de uma reflexão mais profunda sobre a insuficiência de políticas focalizadas nos rendimentos para responder às situações de nova pobreza, bem como a necessidade de promover mudanças estruturais, seja no mercado de trabalho, na justiça, na fiscalidade, na educação, seja nas políticas sociais, que conduzam a uma transformação efectiva e consistente das condições de vida das populações e dos territórios. A diminuição das situações de pobreza extrema, por via por exemplo de políticas sociais de cariz essencialmente paliativo, tende a produzir somente efeitos conjunturais se não for acompanhada de reformas estruturais que permitam consolidar as mudanças em curso e diminuir, de forma persistente, o fosso das desigualdades entre grupos populacionais e regiões.

Nesta medida, o questionamento das desigualdades socioeconómicas ilegítimas continua a constituir-se, e cada vez mais, como um desafio muito relevante em ambos os países, obrigando a um reequilíbrio entre justiça social e eficiência económica, entre bem-estar colectivo e interesses/preferências individuais, na base de um novo contrato social ancorado num ethos global de solidariedade e humanismo, que os processos de globalização podem ajudar a consubstanciar ou a diluir.

\section{Referências bibliográficas}

Anderson, Perry (1995), "Balanço do Neoliberalismo", in Emir Sader e Pablo Gentile (orgs.), Pós-neoliberalismo: as políticas sociais e o Estado democrático. São Paulo: Paz e Terra, 9-23.

Baltar, Paulo; Deddeca, Cláudio (1997), "Mercado de trabalho e informalidade nos anos 90”, Estudos Económicos, IPE-USP, n. ${ }^{\circ}$ especial, 65-84.

Bourdieu, Pierre (org.) (1993), La misère du monde. Paris: Seuil.

Caire, Guy (1982), "Précarisation des emplois et régulation du marché du travail", Sociologie du Travail, 2, 135-158.

Candel, Francesco (1988), La nueva pobreza. Barcelona: Ediciones 62.

Castel, Robert (1995), Les métamorphoses de la question sociale. Une chronique du salariat. Paris: Librairie Arthème Fayard.

Chomsky, Noam (1996), Novas e velhas ordens mundiais. S. Paulo: Scritta.

Comissão Nacional do Rendimento Mínimo (2002), Avaliação de impactes do Rendimento Mínimo Garantido. Lisboa: Instituto para o Desenvolvimento Social. 
Costa, Alfredo Bruto da (coord.) (2008), Um olhar sobre a pobreza. Vulnerabilidade e exclusão social no Portugal contemporâneo. Lisboa: Gradiva.

Delgado, Guilherme Costa (2004), "O setor de subsistência na economia e na sociedade brasileira: gênese histórica, reprodução e configuração contemporânea”, IPEA: Texto para discussão n. 1025, 33 pp.

Eurostat (2010), European Union Labour Force Survey (EU LSF). http://epp.eurostat. ec.europa.eu/portal/page/portal/microdata/lfs/. Acesso em Junho 2011.

Eurostat (2011), News Release Euroindicators. Seasonally Adjusted Unemployment Rates. http://europa.eu/rapid/pressReleasesAction.do? reference $=$ STAT/11/76\&type $=H$ TML. Acesso em Abril 2011.

Estanque, Elísio (2005), “Trabalho, desigualdades sociais e sindicalismo”, Revista Crítica de Ciências Sociais, 71, 113-140.

Estivill, Jordi (2003), Panorama da Luta contra a exclusão social. Bureau Internacional du Travail, STEP/Portugal. http://www.ilo.org/public/portugue/region/eurpro/ lisbon/pdf/panorama.pdf Acesso em 25 Abril 2011.

Ferrera, Maurizio; Hemerijck, Anton; Rhodes, Martin (2011), The Future of European Welfare States. Oxford: Oxford University Press.

Giddens, Anthony (1990), The Consequences of Modernity. Oxford: Polity Press.

Gonçalves, Andrade; Junior, Thomaz (2002), “A informalidade e a precarização do trabalho: uma contribuição à geografia do trabalho”, Scripta Nova-Revista Electrónica de Geografía e Ciencias Sociales, Vol. VI, 119 (31). http://www.ub.edu/geocrit/sn/ sn119-31.htm. Acesso em Julho 2011.

Hespanha, Pedro; Carapinheiro, Graça (orgs) (2001), Risco social e incerteza. Pode o Estado-Providencia recuar mais? Porto: Afrontamento.

Hespanha, Pedro (org.) (2007), É o (des) emprego fonte de pobreza? O impacto do desemprego e do mau emprego na pobreza e exclusão social do Distrito de Coimbra. Coimbra: REAPN.

IBGE - Instituto Brasileiro de Geografia e Estatística (2010). http://www.ibge.gov.br/ home/estatistica/populacao/mapa_mercado_trabalho/default.shtm. Acesso Junho 2011.

ILO - International Labour Organization (2009), Global Employment Trends January 2009.http://www.ilo.org/wcmsp5/groups/public/@dgreports/@dcomm/documents/ publication/wcms_101461.pdf. Acesso em Dezembro 2010.

INE - Instituto Nacional de Estatística (2010). Anuário Estatístico de Portugal 2009. www. ine.pt/xportal/xmain? xpid=INE\&xpgid=ine_publicacoes\&PUBLICACOESpub_ boui=104996740\&PUBLICACOESmodo=2. Acesso em Junho 2011.

INE - Instituto Nacional de Estatística (2011), "Estatística do Emprego. Resultados do Inquérito ao Emprego relativos ao 1. ${ }^{\circ}$ trimestre de 2011 com a adopção da nova metodologia”, Destaque. Informação à Comunicação Social, 18 maio 2011. http:// www.ine.pt. Acesso Abril 2011. 
IPEA - Instituto de Pesquisa Econômica Aplicada (2010), Perspectivas do Desenvolvimento. http://www.ipea.gov.br/portal/images/stories/PDFs/livros/livros/ livro10_perspectivasdodesenvolvimento.pdf . Acesso em Abril 2011.

IPEAData. http://www.ipeadata.gov.br/Default.aspx. Acesso em Abril 2011.

Lavinas, Lena; Sorj, Bila; Linhares, Leila; Jorge, Angela (1998), Trabalho a domicílio. Novas formas de contratação. Genebra: OIT-Departamento de políticas de Desenvolvimento. http://www.ilo.org/public/portugue/employment/strat/download/ iddp30.pdf. Acesso em Abril 2011.

Leite, Márcia (2009), "El trabajo y sus reconfiguraciones: las nuevas condiciones de trabajo discutidas a partir de conceptos y realidades”, Revista Latinoamericana de Estudios del Trabajo, 21, 7-33.

Lima, Jacob Carlos (org.) (2008), Ligações perigosas: trabalho flexivel e trabalho associado. São Paulo: Anablume.

Lipietz, Alain (1992), Towards a New Economic Order. Post-fordism, Ecology and Democracy. New York: Oxford University Press.

Mattoso, Jorge (2001), O Brasil desempregado. São Paulo: Ed. Fundação Perseu Abramo. Murray, Warwick (2006), Geographies of Globalization. New York: Routledge.

Noronha, Eduardo (2003), “'Informal', ilegal e injusto: percepções do mercado de trabalho no Brasil, Revista Brasileira de Ciências Sociais, 53 (18), 111-129.

OECD (2011), Society at a Glance 2011: OECD Social Indicators. http://www.oecd. org/els/social/indicators/SAG ou http://www.portugal-ocde.com/destaques. php?destaque=79. Acesso em Abril 2011.

Offe, Claus (1989), Capitalismo desorganizado. Transformações contemporâneas do trabalho e da politica. S. Paulo: Brasiliense.

Paugam, Serge (org.) (1996), L'exclusion: L'état des savoirs. Paris: La Découverte.

Pochmann, Márcio (2001), O emprego na globalização. São Paulo: Boitempo.

Pochmann, Márcio; Salas, Carlos; Leite, Marcia (2007), "Mercado de trabajo: qué hay de nuevo en Brasil?”, Trabajo, 3 (4), 161-179.

PORData. Subtema "Empresas e Pessoal/ Empresas”. http://www.pordata.pt/site/ ThemeSubThemes.aspx?ThemeId=4. Acesso em Abril 2011.

Portes, Alejandro; Castells, Manuel; Benton, Lauren (orgs.) (1989), The Informal Economy. Studies in Advanced and Less Developed Countries. Baltimore: The John Hopkins University Press.

Reich, Robert (2001), The Future of Success. Working and Living in the New Economy. New York: Alfred A. Knopt.

Rodgers, Gerry; Rodgers, Janine (orgs.) (1989), Precarious Jobs in Labour Market Regulation. The Growth of Atypical Employment in Western Europe. IILS: Free University Press.

Rodrigues, Carlos Farinha (coord.) (2011), Desigualdade em Portugal. Conclusões preliminares. Lisboa: Fundação Francisco Manuel dos Santos. 
Room, Graham (1990), 'New Poverty' in the European Community. London: St. Martin's. Santos, Boaventura de Sousa (2001), Globalização: fatalidade ou utopia. Porto: Afrontamento.

Saraceno, Chiara (1990), "Nuove povertà o nuovi rischi di povertà", in Nicola Negri (org.), Povertà in Europa e trasformazione dello stato sociale. Milão: Franco Angeli, 249-276.

Schnapper, Dominique (1998), Contra o fim do Trabalho. Lisboa: Terramar.

Sennett, Richard (2001), A corrosão do carácter. As consequências do trabalbo no novo capitalismo. Lisboa: Terramar.

Sklair, Leslie (1991), Sociology of the Global System. London: Harvester Wheatsheaf.

Tokman, Victor (2004), Una voz en el camino. Empleo y equidad en America Latina. 40 años de búsqueda. México: Fondo de Cultura Economica.

Wallerstein, Immanuel (1991), The Capitalist World-Economy. Cambridge: Cambridge University Press.

Wanderley, Mariângela B. (2001), "Refletindo sobre a noção de exclusão", in Bader Sawaia (org.), As artimanhas da exclusão social: uma análise psicossocial e ética da desigualdade social. Petrópolis: Vozes, 16-26. 